\title{
Locomotive syndrome: clinical perspectives
}

This article was published in the following Dove Press journal:

Clinical Interventions in Aging

\section{Tatsunori Ikemoto' \\ Young-Chang Arai ${ }^{2}$}

'Department of Orthopaedic Surgery, Aichi Medical University, Yazako Karimata, Nagakute, Aichi, Japan; ${ }^{2}$ Institute of Physical Fitness, Sports Medicine and Rehabilitation, Aichi Medical University, Yazako Karimata, Nagakute, Aichi, Japan
Correspondence: Tatsunori lkemoto Department of Orthopaedic Surgery, Aichi Medical University, I-I Yazako Karimata, Nagakute, Aichi 480-I I95, Japan

Tel $+8|56| 621087$

Fax +8I 56I 634707

Email tatsunon3I-ik@umin.ac.jp

\begin{abstract}
The deterioration of locomotive components, which comprise bones, joints, and intervertebral discs, and muscles and nerves, can lead to symptoms such as pain, limitations in the range of joint mobility, malalignment, impaired balance, and difficulty walking. Locomotive syndrome (LoS) was proposed by the Japanese Orthopedic Association in 2007 as a concept for people who are at a high risk of developing a musculoskeletal ambulation disability attributed to locomotor organs. Although many international articles related to LoS have been published, an international consensus of this concept seems to be lacking. This review article on LoS introduces the concept, the related assessment methods, and the condition's prevalence based on the most up-to-date literature, and discusses discrimination from frailty and sarcopenia, relevance to musculoskeletal problems, management plan, and future directions. Familiarity with recent evidence would be useful for the health care providers in an aging society to educate individuals with LoS or pre-LoS and to maintain their well-being and prevent them from requiring long-term care.
\end{abstract}

Keywords: locomotive syndrome, long-term care, frailty, sarcopenia, functional disability, osteoarthritis, spondylosis, osteoporosis

\section{Introduction}

As the number of elderly people needing nursing care is increasing annually and in response to the heavy financial burden this has imposed on the Japanese society, the Japanese government has introduced a new insurance system called Long-term Care Insurance in 2000 to cope with the rapid increase in the aging population. ${ }^{1}$ In this context, three professional Japanese medical societies related to musculoskeletal disorders - the Japanese Orthopedic Association (JOA), the Japanese Society for Musculoskeletal Medicine (formerly the Japanese Society for Musculoskeletal Rehabilitation), and the Japanese Clinical Orthopedic Association - proposed a new concept called musculoskeletal ambulation disability symptoms in 2006 to describe a condition characterized by unstable balance or difficulty walking. ${ }^{2}$ Locomotive syndrome (LoS) was described by the JOA in 2007 as a wider range of disabilities than musculoskeletal ambulation disability symptoms. ${ }^{2,3}$

Although awareness of the concept of LoS has increased in $\mathrm{Japan}^{4}$ and numerous reports on LoS have been published in international journals during the past decade, as determined by a MEDLINE search, these reports have been limited to Japanese institutes and a few articles from other countries have been published, with the exception of a report from Brazil. ${ }^{5}$ This review article on LoS introduces the concept, the related assessment methods, and the condition's prevalence based on previous literature, and discusses discrimination from frailty and sarcopenia, relevance to musculoskeletal problems, management plan, and future directions. The authors reviewed the available literature, reports, and surveys related to LoS available in PubMed/MEDLINE and Google Scholar, on websites, and from other sources up to December 2017. 


\section{Review of literature Concept of LoS}

LoS is proposed as a disorder that predominantly affects people who are at a high risk of developing a musculoskeletal ambulation disability attributed to locomotor organ diseases. ${ }^{3}$ According to the recent literature, $\operatorname{LoS}$ is also defined as a condition in which mobility functions, such as sit-to-stand or gait, are reduced because of locomotive organ impairment. ${ }^{4}$ In LoS, the locomotive system consists of three main components: 1) bones, 2) joints and intervertebral discs, and 3) muscles and nerves. Thus, musculoskeletal ambulation diseases, such as osteoporosis, osteoporosis-related fractures, osteoarthritis (OA), spondylosis, sarcopenia, and neural disorders, are often included in this category. ${ }^{4,6}$ The deterioration of locomotive components or interrelated discordance of the locomotive system can lead to symptoms such as pain, a limitation in the range of joint mobility, malalignment, impaired balance, and difficulty walking ${ }^{4,6}$ (Figure 1). Notably, the condition referred to as "sarcopenia" in a diagram is not the same as "sarcopenia" as defined by the European Working Group or the Asian Working Group.

Degenerative changes in the locomotive organ begin before middle age. For instance, according to Cheung et al $\sim 40 \%$ of people under 30 years of age and $90 \%$ of people over 55 years of age present with intervertebral disc degeneration of the lumbar spine. ${ }^{7}$ A cohort study conducted in Japan has revealed estimated prevalences of radiographic knee OA and lumbar spondylosis of 25.3 and 37.9 million, respectively. ${ }^{8}$ However, as the normal aging process and pathologic changes are often difficult to distinguish based on radiographic degeneration,,$^{9,10}$ health education has been an essential component in promoting health and preventing disease. ${ }^{11}$

\section{Assessment of LoS}

Several assessment methods have been proposed to examine elderly people with a functional decline and to establish an operational definition of $\operatorname{LoS} .^{5,12-18}$

Initially, when the concept of LoS was proposed, seven self-check statements were prepared to determine whether the patient presented with an element of LoS. ${ }^{5}$ Several international research articles have adopted this assessment to determine the presence or absence of LoS over the past decade. However, this assessment has been used only for selfencouragement as an accessible term known as loco-check, ${ }^{19}$ but not for the operational definition of LoS according to the official announcement by the JOA (https://locomo-joa. jp/locomo/).

In 2008, a research group of the Ministry of Health, Labor, and Welfare in Japan ${ }^{20}$ established a diagnostic tool for LoS by organizing a group of six experts, who developed the 25-question Geriatric Locomotive Function Scale (GLFS-25). This scale is a tool to assess difficulty and disability in daily activities related to locomotive organs. ${ }^{12}$

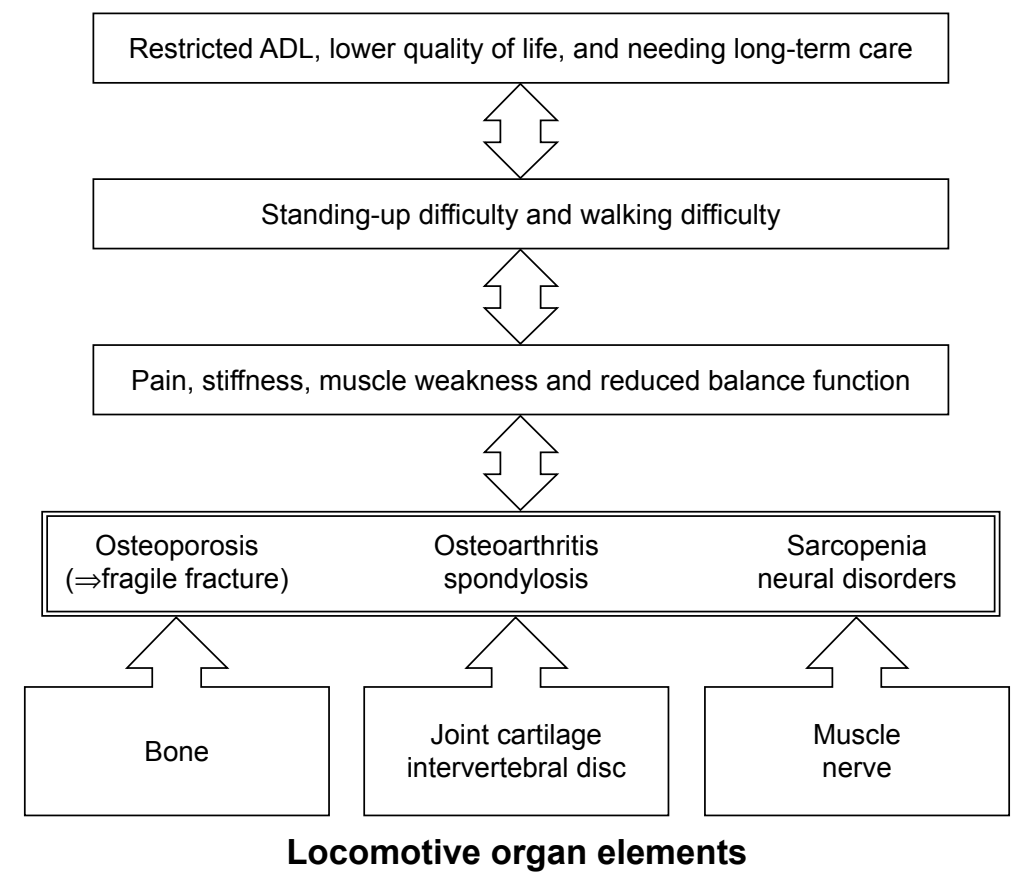

Figure I A concept of locomotive syndrome. Abbreviation: ADL, activities of daily living. 
Table I Reference values of physical performance tests for LoS

\begin{tabular}{|c|c|c|c|}
\hline References & Samples & Test items & Main findings \\
\hline Yoshimura et al ${ }^{13}$ & $\begin{array}{l}\geq 40 \text { years, } \\
826 \text { men, } \\
\text { I,642 women }\end{array}$ & $\begin{array}{l}\text { Hand grip strength } \\
\text { One-leg standing time } \\
6 \mathrm{MWT}\end{array}$ & $\begin{array}{l}\text { - Mean values for hand grip strength, waking time for } 6 \mathrm{~m} \text { at usual pace, and fast } \\
\text { pace for men were } 32.7 \mathrm{~kg}, 5.6 \text { and } 3.7 \mathrm{~s} \text {, respectively, and those for women } \\
\text { were } 32.7 \mathrm{~kg}, 5.6 \text { and } 3.7 \mathrm{~s} \text {, respectively } \\
\text { - Median values for one-leg standing time were } 14 \mathrm{~s} \text { for men and } 12 \mathrm{~s} \text { for women } \\
\text { - There were significant associations between the presence of disability and } \\
\text { walking speed }\end{array}$ \\
\hline Muramoto et $\mathrm{al}^{14}$ & $\begin{array}{l}\geq 40 \text { years, } \\
128 \text { men, } \\
230 \text { women }\end{array}$ & $\begin{array}{l}\text { Hand grip strength } \\
\text { One-leg standing time } \\
\text { Timed up-and-go test } \\
\text { I0 m gait time } \\
\text { Back muscle strength } \\
\text { Maximum stride }\end{array}$ & $\begin{array}{l}\text { - Hand grip strength, one-leg standing time, and timed up-and-go test proved } \\
\text { to be reliable performance tests to evaluate the severity of LoS }\end{array}$ \\
\hline Muramoto et $\mathrm{al}^{15}$ & $\begin{array}{l}\geq 60 \text { years, } \\
128 \text { men, } \\
230 \text { women }\end{array}$ & Same as above & $\begin{array}{l}\text { When using a GLFS-25 score ( } \geq 16) \text {, reference values for timed up-and-go test, } \\
\text { one-leg standing time, back muscle strength, } 10 \mathrm{~m} \text { gait time, maximum stride, } \\
\text { and grip strength in men were } 6.7 \text { and } 21 \mathrm{~s}, 78 \mathrm{~kg}, 5.5 \mathrm{~s}, 119 \mathrm{~cm} \text {, and } 34 \mathrm{~kg} \text {, } \\
\text { respectively, and those for women were } 7.5 \text { and } 15 \mathrm{~s}, 40 \mathrm{~kg}, 6.2 \mathrm{~s}, 104 \mathrm{~cm} \text {, } \\
\text { and } 22 \mathrm{~kg} \text {, respectively }\end{array}$ \\
\hline Nakamura et al $^{16}$ & $\begin{array}{l}\geq 65 \text { years, } \\
126 \text { women }\end{array}$ & $\begin{array}{l}\text { Hand grip strength } \\
\text { One-leg standing time } \\
\text { Seated toe touch } \\
6 \mathrm{MWT}\end{array}$ & $\begin{array}{l}\text { When using a GLFS-25 score }(\geq 16) \text {, the threshold for discriminating LoS } \\
\text { was } 15 \mathrm{~s} \text { for one-leg standing time, } 4.8 \mathrm{~s} \text { for normal } 6 \mathrm{MWT} \text {, and } 3.6 \mathrm{~s} \text { for fast } \\
6 \mathrm{MWT} \text {. Of these variables, one-leg standing time }<15 \mathrm{~s} \text { was most strongly } \\
\text { associated with LoS }\end{array}$ \\
\hline Seichi et al $^{17}$ & $\begin{array}{l}\geq 65 \text { years, } \\
261 \text { men, } \\
619 \text { women }\end{array}$ & $\begin{array}{l}\text { The average of one-leg } \\
\text { standing time obtained } \\
\text { for both legs (IA-OLS) }\end{array}$ & $\begin{array}{l}\text { When using a GLFS- } 25 \text { score }(\geq 16) \text {, the optimal cutoff for IA-OLS time was } \\
19 \mathrm{~s} \text { for individuals aged } \leq 70,10 \mathrm{~s} \text { for individuals aged }>70 \text { and } \leq 75 \text {, and } 6 \mathrm{~s} \\
\text { for individuals aged }>75\end{array}$ \\
\hline
\end{tabular}

Abbreviations: 6MWT, 6 m walking time; GLFS-25, 25-question Geriatric Locomotive Function Scale; IA-OLS, individual average of one-leg standing time obtained for both legs; LoS, locomotive syndrome.

Indeed, most research articles have adopted the GLFS-25 to determine both the presence and severity of LoS, regardless of the age of the subjects. Subsequently, several functional measures, such as hand grip strength, one-leg standing time, and $6 \mathrm{~m}$ walking time, were proposed to evaluate $\operatorname{LoS}^{13-17}$ (Table 1). Although these methods seemed to be valuable, none was adopted as an official performance test for assessing LoS. Alternatively, Ogata et al have proposed two physical performance tests to evaluate the motor function in people with LoS, including the two-step test and the stand-up test. ${ }^{18}$ Currently, the two-step test, the stand-up test, and the GLFS-25 have been officially introduced to diagnose people with $\operatorname{LoS}^{4,21}$ (Table 2). In the proposed assessments, although two clinical stages of LoS have been defined for assessing the severity of locomotive symptoms, recent

Table 2 Operational definition for locomotive syndrome

\begin{tabular}{lll}
\hline & Stage I & Stage 2 \\
\hline Two-step test & $<\mathrm{I} .3$ & $<\mathrm{I} . \mathrm{I}$ \\
Stand-up test & Impossible to stand & Impossible to stand \\
& up from $40 \mathrm{~cm}$ height & up from $20 \mathrm{~cm}$ height \\
& stool with one leg & stool with both legs \\
GLFS-25 score & $\geq 7$ & $\geq 16$ \\
\hline
\end{tabular}

Abbreviation: GLFS-25, 25-question Geriatric Locomotive Function Scale. literature typically uses stage $2 \operatorname{LoS}$ to determine whether the subject has LoS.

\section{Two-step test}

The subject begins the test in an upright posture and moves forward for a maximum of two strides without losing his or her balance. If the subject succeeds in holding the final standing position for longer than $3 \mathrm{~s}$ without any additional steps, the test is regarded as complete. The test is performed twice, and the best result is recorded. The distance is subsequently standardized according to the subject's height. ${ }^{18}$ If the value of this test is $<1.3$ or 1.1 , the subject is regarded as having stage $1 \mathrm{LoS}$ or stage $2 \mathrm{LoS}$, respectively.,21

\section{Stand-up test}

Subjects are asked to stand from stools of varying heights with a single leg or both legs. The stools range from 10 to $40 \mathrm{~cm}$ in height, increasing in $10 \mathrm{~cm}$ increments. The test is first performed with both legs using the easiest size, namely, the $40 \mathrm{~cm}$ stool, and then using increasingly difficult sizes, with every $10 \mathrm{~cm}$ downward step, followed by a single leg standing test performed in the same manner. If the subject succeeds in holding the final standing position for longer than $3 \mathrm{~s}$ without any additional steps, the test is regarded 
as complete. ${ }^{18}$ If the trial with the $40 \mathrm{~cm}$ tall stool using a single leg is not completed, the subject is regarded as having stage $1 \mathrm{LoS}$, and if the trial with the $20 \mathrm{~cm}$ tall stool using both legs is not completed, the subject is regarded as having stage 2 LoS. ${ }^{4,21}$

The 25-question Geriatric Locomotive Function Scale The GLFS-25 is a self-reported comprehensive measure that consists of 25 questions that refer to experiences in the preceding month. The scale addresses four dimensions with 25 questions: 4 questions regarding pain, 16 questions regarding activities of daily living, 3 questions regarding social functions, and 2 questions regarding mental health status. Each of the questions is rated on an ordinal scale of 0-4 points, with higher scores indicating a symptom or a medical condition of greater severity. In previous studies, the GLFS-5 was also introduced as a quick fiveitem version of the GLFS-25 using a cluster analysis. The total score is assumed to represent a quantitative evaluation of the difficulties and disabilities in daily life activities related to locomotive organs. The cutoff scores for identifying LoS were set to 16 for the total score (ranging from 0 to 100 points) for GLFS-25 and 6 for the total score (ranging from 0 to 20 points) for GLFS-5, respectively. ${ }^{12}$ On the other hand, a GLFS-25 score of $\geq 7$ is regarded as stage $1 \mathrm{LoS}$ and a GLFS-25 score of $\geq 16$ is regarded as stage 2 LoS. ${ }^{4,21}$

Akai et al recently evaluated the relationships between the GLFS-25 score and 46 variables in multiple dimensions, including demographic background, living environment, health status, medical history and comorbidity, locomotive organ problems, clinical symptoms, laboratory tests, X-ray findings, and motor functional assessment. Eleven variables were identified. The authors reported that the GLSF-25 score showed an increasing negative correlation with each variable in the following order: ${ }^{22}$

- Use of a walking aid

- Daily tasks are bothersome to complete

- Weakness of the triceps surae muscle

- Sensory changes in the lower leg

- Muscle weakness in the anterior tibial muscle

- Difficulty seeing

- Knee joint pain

- Difficulty hearing

- Low back pain

- Sense of powerlessness

- Weakness of the quadriceps muscle

\section{Prevalence}

Two nationwide surveys reported the prevalence of LoS in people aged $\geq 40$ years in Japan using the cutoff $\geq 16$ for the GLFS-25 score. The estimated prevalence of LoS was 7.9\% in men and $12.3 \%$ in women in $2010^{23}$ and $10.8 \%$ in men and $12.9 \%$ in women in $2014 .{ }^{24}$ Moreover, Yoshimura et al investigated the prevalence of LoS using the new indices of the two-stage definition in 2013 and revealed that the estimated prevalence of stage 1 LoS (GLFS-25 score $\geq 7$ ) was $18.8 \%$ in men and $24.5 \%$ in women and of stage 2 LoS (GLFS-25 score $\geq 16$ ) was $9.0 \%$ in men and $11.4 \%$ in women. ${ }^{21}$ Based on these reports, the prevalence of LoS, as defined by the cutoff score $(\geq 16)$ for GLFS-25, consistently increases in patients aged $\geq 70$ years, and women in all generations are more likely to develop LoS (Table 3).

\section{Discussion}

\section{Conceptual differences between frailty, sarcopenia, and LoS}

Considerable overlap exists among frailty, sarcopenia, and LoS, particularly in terms of the physical aspect of functional decline. However, each concept develops in different circumstances.

Frailty is conceptually characterized as a clinically vulnerable state in older adults that results from an age-associated decline in multiple organ systems, ${ }^{25-27}$ whereas sarcopenia and LoS mainly focus on mobile capacity. Frailty includes a variety of functional deficits that occur during aging, such as comorbid illnesses, psychological vulnerability, self-reported disability, and poor quality of life. Two major definitions of frailty have emerged over the past several years: the frailty phenotype, which is known as Fried's definition, ${ }^{25}$ and the frailty index. ${ }^{26}$ Moreover, further definitive criteria have also been described in the literature. ${ }^{27}$

The term sarcopenia was initially proposed in $1989 .{ }^{28,29}$ This disorder has been recognized as the loss of muscle function and the loss of muscle mass with aging. According to the European Working Group, sarcopenia requires the presence of either a low gait speed or low grip strength prior to the loss of muscle mass, ${ }^{30}$ and this algorithm was adopted by the Asian Working Group for sarcopenia, with some differences in the cutoff values. ${ }^{31}$ Therefore, distinctive feature of sarcopenia seems to have a definitive algorithm to clarify this condition.

Although the concepts seem to differ from each other, substantial overlap in the physical aspect of functional decline exists among these three syndromes. In fact, with respect to 
Table 3 Estimated prevalence of locomotive syndrome in Japan

\begin{tabular}{|c|c|c|c|c|c|c|c|c|}
\hline \multicolumn{3}{|l|}{ Demographics } & \multicolumn{2}{|c|}{ Two-step test } & \multicolumn{2}{|c|}{ Stand-up test } & \multicolumn{2}{|c|}{ GLFS- 25 score } \\
\hline & & & Stage I & Stage 2 & Stage I & Stage 2 & Stage I & Stage 2 \\
\hline \multirow[t]{8}{*}{ Kimura et $\mathrm{al}^{23}$} & \multirow[t]{2}{*}{$40 \mathrm{~s}$} & Men & \multirow[t]{8}{*}{ None } & & & & \multirow[t]{8}{*}{ None } & $8.0 \%$ \\
\hline & & Women & & & & & & $8.9 \%$ \\
\hline & \multirow[t]{2}{*}{$50 \mathrm{~s}$} & Men & & & & & & $7.9 \%$ \\
\hline & & Women & & & & & & $10.4 \%$ \\
\hline & \multirow[t]{2}{*}{$60 \mathrm{~s}$} & Men & & & & & & $6.0 \%$ \\
\hline & & Women & & & & & & $10.5 \%$ \\
\hline & \multirow[t]{2}{*}{70 s } & Men & & & & & & $10.8 \%$ \\
\hline & & Women & & & & & & $20.8 \%$ \\
\hline \multirow[t]{8}{*}{ Seichi et a ${ }^{24}$} & \multirow[t]{2}{*}{$40 \mathrm{~s}$} & Men & \multirow{8}{*}{\multicolumn{2}{|c|}{ None }} & & & \multirow[t]{8}{*}{ None } & $4.4 \%$ \\
\hline & & Women & & & & & & $4.8 \%$ \\
\hline & \multirow[t]{2}{*}{$50 \mathrm{~s}$} & Men & & & & & & $7.2 \%$ \\
\hline & & Women & & & & & & $8.3 \%$ \\
\hline & \multirow[t]{2}{*}{$60 \mathrm{~s}$} & Men & & & & & & $11.5 \%$ \\
\hline & & Women & & & & & & $12.5 \%$ \\
\hline & \multirow[t]{2}{*}{70 s } & Men & & & & & & $21.1 \%$ \\
\hline & & Women & & & & & & $27.5 \%$ \\
\hline \multirow[t]{8}{*}{ Yoshimura et al ${ }^{21}$} & \multirow[t]{2}{*}{$40 s$} & Men & $21.1 \%$ & $2.6 \%$ & $15.8 \%$ & $2.6 \%$ & $10.8 \%$ & $0.0 \%$ \\
\hline & & Women & $31.8 \%$ & $1.2 \%$ & $12.9 \%$ & $0.0 \%$ & $8.3 \%$ & $2.4 \%$ \\
\hline & \multirow[t]{2}{*}{$50 \mathrm{~s}$} & Men & $34.6 \%$ & $3.7 \%$ & $15.9 \%$ & $0.0 \%$ & $7.4 \%$ & $1.2 \%$ \\
\hline & & Women & $31.8 \%$ & $3.1 \%$ & $23.6 \%$ & $1.0 \%$ & $13.0 \%$ & $4.2 \%$ \\
\hline & \multirow[t]{2}{*}{$60 s$} & Men & $49.3 \%$ & $8.8 \%$ & $47.8 \%$ & $3.7 \%$ & $12.0 \%$ & $6.0 \%$ \\
\hline & & Women & $52.4 \%$ & $12.4 \%$ & $33.9 \%$ & $5.5 \%$ & $19.7 \%$ & $4.6 \%$ \\
\hline & \multirow[t]{2}{*}{$70 s$} & Men & $71.7 \%$ & $23.9 \%$ & $78.0 \%$ & $2.9 \%$ & $19.9 \%$ & $8.1 \%$ \\
\hline & & Women & $78.3 \%$ & $30.4 \%$ & $56.2 \%$ & $13.1 \%$ & $31.6 \%$ & $15.1 \%$ \\
\hline
\end{tabular}

Abbreviation: GLFS-25, 25-question Geriatric Locomotive Function Scale.

walking difficulty, which is a common disability shared by patients with the three syndromes, a large body of evidence has suggested that gait speed is associated with mortality in older adults. ${ }^{32,33}$ Moreover, mental disorders among elderly people were recently found to be associated with sarcopenia $^{34,35}$ and LoS. ${ }^{36,37}$ Therefore, the clinical features of the three conditions are closely linked to each other.

Frailty and sarcopenia can be used to describe the condition of people who show a functional decline that is diagnosed based on several definitive criteria, whereas the concept of disability in LoS remains ambiguous. This ambiguity occurs because LoS includes not only people with a severe disability, but also individuals who are predicted to develop the syndrome in the future. ${ }^{6}$ The early detection of problems related to health and interventions plays a crucial role in helping older people remain independent. ${ }^{38,39}$ According to Iwaya et al limitations in activity might first occur in sports, followed by walking, transferring, and self-care, in that order, and limitations in mobility appear to result in mild disability. ${ }^{40}$ The extension of mild locomotion dysfunction seems to be an additional component of LoS and, thus, can include middle-aged adults (Figure 2).

\section{Association of LoS with musculoskeletal problems}

The degeneration of locomotive organs in knee OA and lumbar spondylosis is an important contributor to LoS by definition. ${ }^{41,42}$ Although approximately linear relationships were observed between the prevalence of radiographic knee OA or lumbar spondylosis and age $>40$ years in both sexes, ${ }^{43}$ the correlation between the prevalence of LoS and age did not seem to be linear. In particular, the prevalence of LoS (GLFS-25 score $\geq 16$ ) in Japanese men in their 40s and 50s was $<10 \%$ (Table 3 ), despite the high incidence of radiographic lumbar spondylosis. ${ }^{8}$ This finding may be explained by the observation that musculoskeletal pain and muscle strength are independent predictors of the severity of LoS. ${ }^{22}$ Numerous previous studies have reported the relationships 


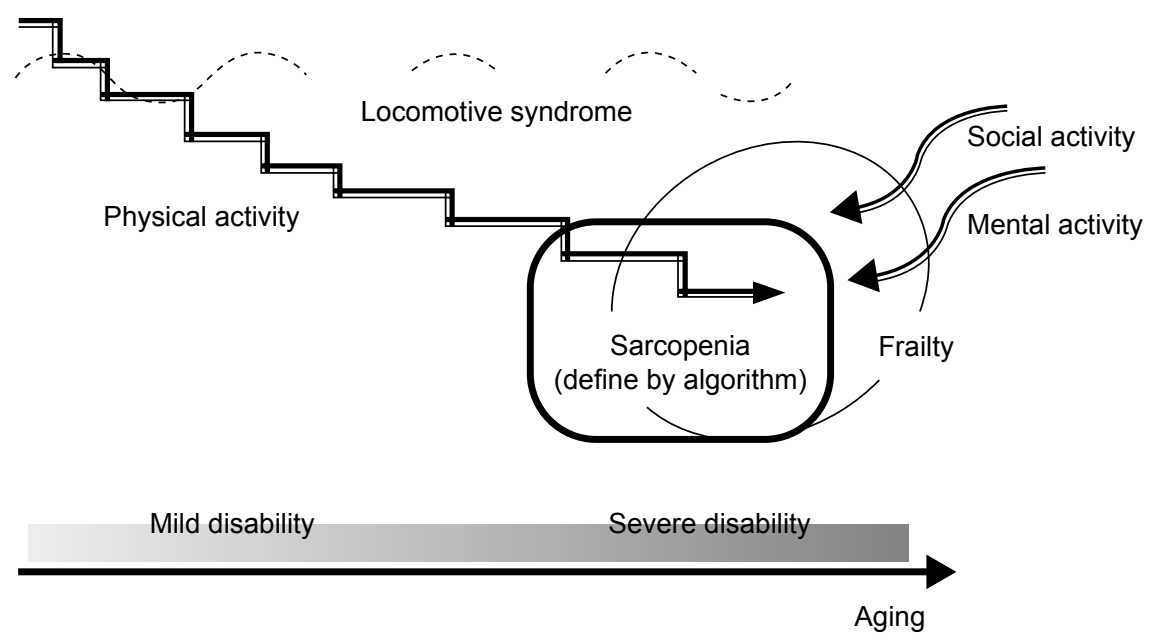

Figure 2 Mutual relationships between locomotive syndrome, frailty, and sarcopenia.

between musculoskeletal pain and LoS. ${ }^{16,44-47}$ Recently, biopsychosocial factors were shown to be essential components associated with not only low back pain ${ }^{48,49}$ but also knee pain, ${ }^{50,51}$ because pain is affected by actual tissue damage and psychological experience. Psychometric properties have been reported to predict pain and disability outcomes not only in patients with low back pain ${ }^{52,53}$ but also in patients with symptomatic knee OA. ${ }^{54,55}$ Thus, biopsychosocial factors should be considered when evaluating people with locomotor disabilities, particularly individuals with chronic pain conditions.

Although muscle strength is also an essential factor associated with locomotor function, ${ }^{14,15,24,36,46,47,56}$ the impact of muscle strength on LoS may be more prominent in women than in men. ${ }^{15}$

In addition, the relationship between osteoporosis and LoS should be mentioned. Osteoporosis has a significant impact on LoS, as it influences the risk of osteoporotic fractures accompanied by low-energy trauma and occasionally results in a patient becoming bedridden. In general, bone mineral density (BMD) is assessed using dual-energy X-ray absorptiometry technology to diagnose osteoporosis. ${ }^{57}$ According to several studies, decreased physical performance is associated with a low BMD. ${ }^{58,59}$ However, no study in the previous literature investigated the relationship between osteoporosis assessed by determining the BMD of the lumbar spine or the femoral neck and the presence or absence of LoS, although two reports investigating this relationship assessed the BMD of the calcaneus. ${ }^{41,45}$ Lumbar degenerative spondylosis occurring concomitantly with osteophytes, endplate sclerosis, facet degenerations, vertebral rotations, and possibly aortic calcifications has been reported to result in falsely elevated BMD values measured using dual-energy
X-ray absorptiometry, and thus, a discordant relationship between the BMD values for the lumbar spine and femoral neck would be observed. ${ }^{60,61}$ Therefore, we speculate that patients with early stage of LoS do not show decreased BMD values.

\section{Prevention or management of LoS}

Based on accumulating evidence, exercise prescriptions significantly contribute to the maintenance of functional capacity in elderly people. ${ }^{62,63}$ Although only one intervention trial for elderly people with LoS has been performed, ${ }^{64}$ another exercise intervention for community-dwelling elderly people has been reported in Japan. ${ }^{65}$ Both reports recorded significant improvements in the physical function of the participants after each intervention. The JOA has officially proposed locomotion training, called locotra, with the aim of improving and sustaining physical function in middleand older-aged subjects. ${ }^{66}$ Locotra consists of squatting and standing on a single leg with the eyes open, and has been shown to be effective and convenient and can improve physical function in elderly people. ${ }^{67}$ However, further randomized controlled intervention trials are necessary to validate the evidence.

In addition to the physical interventions, a psychosocial approach should be used to maintain and encourage adherence, defined as the extent to which subjects follow the recommendations, by people with LoS. Most intervention trials generally aim to improve the study outcome immediately after each intervention; however, researchers do not typically determine whether the effect is maintained beyond the end of the intervention. ${ }^{63}$ DiMatteo reported that the average nonadherence rate was $24.8 \%$ among patients with various disease conditions. ${ }^{68}$ The World Health Organization 
proposes that adherence is not only affected by disease and treatment, but also by the health care system or the providerpatient relationship, patient characteristics, and socioeconomic factors. ${ }^{69}$ According to Inoue et al a combination of psychosocial and physical interventions might significantly improve long-term GLFS-25 score and pain-related outcomes in patients with refractory chronic pain. ${ }^{70}$ Based on recent evidence, multidisciplinary biopsychosocial rehabilitation has positive effects on pain and disabilities in patients with chronic low back pain. ${ }^{71}$ Thus, a multifaceted approach has been suggested to enhance the self-care ability of patients and enable them to maintain an exercise routine.

\section{Future directions}

The concept of LoS has become widespread in Japan. Thus, several relevant studies are underway. The LoS and Health Outcome in Aizu Cohort Study was initiated to focus on the relationships between various diseases and the function of the cervical and lumbar spine and the upper and lower extremities. ${ }^{72}$ Studies have reported the prevalence of cardiovascular disease, diabetes, pterygium, and depression in this population. In addition, the LoS and Health Outcome in Aizu Cohort Study has reported the relationships between future risk of falls and kyphotic posture, subjective sleep patterns, and subjective fatigue in cohort studies. ${ }^{73-75}$ Additional evidence would be helpful in enabling people with LoS or pre-LoS in Japan to maintain their well-being and prevent them from requiring long-term care or becoming bedridden.

Finally, we must note that with the exception of Japanese scholars, international researchers have rarely published articles related to LoS; thus, an international consensus has not yet been established. The aging of society is not a problem exclusive to Japan; thus, international collaborations are needed for the concept of LoS to be disseminated worldwide.

\section{Disclosure}

The authors report no conflicts of interest in this work.

\section{References}

1. Matsuda S, Yamamoto M. Long-term care insurance and integrated care for the aged in Japan. Int J Integr Care. 2001;1:e28.

2. Hoshino Y. [Concept of musculoskeletal ambulation disability symptom complex (MADS)]. Clin Calcium. 2008;18(11):1553-1558. Japanese.

3. Nakamura K. A "super-aged" society and the "locomotive syndrome". J Orthop Sci. 2008;13(1):1-2.

4. Nakamura K, Ogata T. Locomotive syndrome: definition and management. Clin Rev Bone Miner Metab. 2016;14(2):56-67.

5. Tavares DR, Santos FC. Síndrome locomotora em idosos: tradução, adaptação cultural e validação brasileira do instrumento 25-Question Geriatric Locomotive Function Scale [Locomotive syndrome in the elderly: translation, cultural adaptation, and Brazilian validation of the tool 25-Question Geriatric Locomotive Function Scale]. Rev Bras Reumatol Engl Ed. 2017;57(1):56-63. Portuguese.
6. Nakamura K. The concept and treatment of locomotive syndrome: its acceptance and spread in Japan. J Orthop Sci. 2011;16(5):489-491.

7. Cheung KM, Karppinen J, Chan D, et al. Prevalence and pattern of lumbar magnetic resonance imaging changes in a population study of one thousand forty-three individuals. Spine (Phila Pa 1976). 2009;34(9):934-940.

8. Yoshimura N, Muraki S, Oka H, et al. Prevalence of knee osteoarthritis, lumbar spondylosis, and osteoporosis in Japanese men and women: the research on osteoarthritis/osteoporosis against disability study. J Bone Miner Metab. 2009;27(5):620-628.

9. Bedson J, Croft PR. The discordance between clinical and radiographic knee osteoarthritis: a systematic search and summary of the literature. BMC Musculoskelet Disord. 2008;9:116.

10. Brinjikji W, Luetmer PH, Comstock B, et al. Systematic literature review of imaging features of spinal degeneration in asymptomatic populations. AJNR Am J Neuroradiol. 2015;36(4):811-816.

11. Nutbeam D. Health literacy as a public health goal: a challenge for contemporary health education and communication strategies into the 21 th century. Heal Prom Int. 2000;15(3):259-267.

12. Seichi A, Hoshino Y, Doi T, Akai M, Tobimatsu Y, Iwaya T. Development of a screening tool for risk of locomotive syndrome in the elderly: the 25-question Geriatric Locomotive Function Scale. J Orthop Sci. 2012;17(2):163-172.

13. Yoshimura N, Oka H, Muraki S, et al. Reference values for hand grip strength, muscle mass, walking time, and one-leg standing time as indices for locomotive syndrome and associated disability: the second survey of the ROAD study. J Orthop Sci. 2011;16(6):768-777.

14. Muramoto A, Imagama S, Ito Z, Hirano K, Ishiguro N, Hasegawa Y. Physical performance tests are useful for evaluating and monitoring the severity of locomotive syndrome. J Orthop Sci. 2012;17(6):782-788.

15. Muramoto A, Imagama S, Ito $Z$, et al. Threshold values of physical performance tests for locomotive syndrome. J Orthop Sci. 2013;18(4): 618-626.

16. Nakamura M, Hashizume H, Oka H, et al. Physical performance measures associated with locomotive syndrome in middle-aged and older Japanese women. J Geriatr Phys Ther. 2015;38(4):202-207.

17. Seichi A, Hoshino Y, Doi T, et al. Determination of the optimal cutoff time to use when screening elderly people for locomotive syndrome using the one-leg standing test (with eyes open). J Orthop Sci. 2014;19(4): 620-626.

18. Ogata T, Muranaga S, Ishibashi H, et al. Development of a screening program to assess motor function in the adult population: a crosssectional observational study. J Orthop Sci. 2015;20(5):888-895.

19. Akahane M, Maeyashiki A, Yoshihara S, Tanaka Y, Imamura T. Relationship between difficulties in daily activities and falling: loco-check as a self-assessment of fall risk. Interact J Med Res. 2016;5(2):e20.

20. Hoshino Y. Development of an early detection tool for locomotive dysfunction. A report of Ministry of Health, Labor and Welfare. 2009; 200821064A. Japanese. Available from: http://mhlw-grants.niph. go.jp/niph/search/NIDD00.do?resrchNum=200821064A. Accessed December 1, 2017.

21. Yoshimura N, Muraki S, Oka H, et al. Association between new indices in the locomotive syndrome risk test and decline in mobility: third survey of the ROAD study. J Orthop Sci. 2015;20(5):896-905.

22. Akai M, Doi T, Seichi A, Okuma Y, Ogata T, Iwaya T. Locomotive syndrome: operational definition based on a questionnaire, and exercise interventions on mobility dysfunction in elderly people. Clin Rev Bone Miner Metab. 2016;14:119-130.

23. Kimura A, Seichi A, Konno S, Yabuki S, Hayashi K. Prevalence of locomotive syndrome in Japan: a nationwide, cross-sectional Internet survey. J Orthop Sci. 2014;19(5):792-797.

24. Seichi A, Kimura A, Konno S, Yabuki S. Epidemiologic survey of locomotive syndrome in Japan. J Orthop Sci. 2016;21(2):222-225.

25. Fried LP, Tangen CM, Walston J, et al; Cardiovascular Health Study Collaborative Research Group. Frailty in older adults: evidence for a phenotype. J Gerontol A Biol Sci Med Sci. 2001;56(3):M146-M157.

26. Jones DM, Song X, Rockwood K. Operationalizing a frailty index from a standardized comprehensive geriatric assessment. J Am Geriatr Soc. 2004;52(11):1929-1933. 
27. Chen X, Mao G, Leng SX. Frailty syndrome: an overview. Clin Interv Aging. 2014;9:433-441.

28. Rosenberg I. Summary comments: epidemiological and methodological problems in determining nutritional status of older persons. Am J Clin Nutr. 1989;50:1231-1233.

29. Rosenberg IH. Sarcopenia: origins and clinical relevance. J Nutr. 1997; 127(5 Suppl):990S-991S.

30. Cruz-Jentoft AJ, Baeyens JP, Bauer JM, et al; European Working Group on Sarcopenia in Older People. Sarcopenia: European consensus on definition and diagnosis: Report of the European Working Group on Sarcopenia in older people. Age Ageing. 2010;39(4):412-423.

31. Chen LK, Liu LK, Woo J, et al. Sarcopenia in Asia: consensus report of the Asian Working Group for Sarcopenia. J Am Med Dir Assoc. 2014; 15(2):95-101.

32. Studenski S, Perera S, Patel K, et al. Gait speed and survival in older adults. JAMA. 2011;305(1):50-58.

33. Stanaway FF, Gnjidic D, Blyth FM, et al. How fast does the Grim Reaper walk? Receiver operating characteristics curve analysis in healthy men aged 70 and over. BMJ. 2011;343:d7679.

34. Hsu YH, Liang CK, Chou MY, et al. Association of cognitive impairment, depressive symptoms and sarcopenia among healthy older men in the veterans retirement community in southern Taiwan: a cross-sectional study. Geriatr Gerontol Int. 2014;14 (Suppl 1):102-108.

35. Manrique-Espinoza B, Salinas-Rodríguez A, Rosas-Carrasco O, Gutiérrez-Robledo LM, Avila-Funes JA. Sarcopenia is associated with physical and mental components of health-related quality of life in older adults. J Am Med Dir Assoc. 2017;18(7):636.e1-636.e5.

36. Ikemoto $\mathrm{T}$, Inoue $\mathrm{M}$, Nakata $\mathrm{M}$, et al. Locomotive syndrome is associated not only with physical capacity but also degree of depression. J Orthop Sci. 2016;21(3):361-365.

37. Nakamura M, Tazaki F, Nomura K, et al. Cognitive impairment associated with locomotive syndrome in community-dwelling elderly women in Japan. Clin Interv Aging. 2017;12:1451-1457.

38. Lette M, Stoop A, Lemmens LC, Buist Y, Baan CA, de Bruin SR. Improving early detection initiatives: a qualitative study exploring perspectives of older people and professionals. BMC Geriatr. 2017;17(1):132.

39. Binder EF, Schechtman KB, Ehsani AA, et al. Effects of exercise training on frailty in community-dwelling older adults: results of a randomized, controlled trial. J Am Geriatr Soc. 2002;50(12):1921-1928.

40. Iwaya T, Doi T, Seichi A, Hoshino Y, Ogata T, Akai M. Characteristics of disability in activity of daily living in elderly people associated with locomotive disorders. BMC Geriatr. 2017;17(1):165.

41. Ohsawa T, Shiozawa H, Saito K, et al. Relation between the stand-up test and gait speed, knee osteoarthritis, and osteoporosis using calcaneal quantitative ultrasound - Cross-sectional study. J Orthop Sci. 2016; 21(1):74-78.

42. Chiba D, Tsuda E, Wada K, et al. Lumbar spondylosis, lumbar spinal stenosis, knee pain, back muscle strength are associated with the locomotive syndrome: rural population study in Japan. J Orthop Sci. 2016; 21(3):366-372.

43. Yoshimura N, Muraki S, Oka H, Kawaguchi H, Nakamura K, Akune T. Cohort profile: research on Osteoarthritis/Osteoporosis Against Disability study. Int J Epidemiol. 2010;39(4):988-995.

44. Hirano K, Imagama S, Hasegawa Y, Ito Z, Muramoto A, Ishiguro N. Impact of low back pain, knee pain, and timed up-and-go test on quality of life in community-living people. J Orthop Sci. 2014;19(1): 164-171.

45. Iizuka Y, Iizuka H, Mieda T, Tajika T, Yamamoto A, Takagishi K. Population-based study of the association of osteoporosis and chronic musculoskeletal pain and locomotive syndrome: the Katashina study. J Orthop Sci. 2015;20(6):1085-1089.

46. Muramoto A, Imagama S, Ito Z, Hirano K, Ishiguro N, Hasegawa Y. Spinal sagittal balance substantially influences locomotive syndrome and physical performance in community-living middle-aged and elderly women. J Orthop Sci. 2016;21(2):216-221.
47. Imagama S, Hasegawa $\mathrm{Y}$, Ando K, et al. Staged decrease of physical ability on the locomotive syndrome risk test is related to neuropathic pain, nociceptive pain, shoulder complaints, and quality of life in middle-aged and elderly people - The utility of the locomotive syndrome risk test. Mod Rheumatol. 2017;27(6):1051-1056.

48. Kikuchi S. New concept for backache: biopsychosocial pain syndrome. Eur Spine J. 2008;17 (Suppl 4):421-427.

49. Kikuchi S. The recent trend in diagnosis and treatment of chronic low back pain. Spine Surg Relat Res. 2017;1(1):1-6.

50. Keefe FJ, Abernethy AP, C Campbell L. Psychological approaches to understanding and treating disease-related pain. Annu Rev Psychol. 2005;56:601-630

51. Keefe FJ, Somers TJ. Psychological approaches to understanding and treating arthritis pain. Nat Rev Rheumatol. 2010;6(4):210-216.

52. Linton SJ, Boersma K. Early identification of patients at risk of developing a persistent back problem: the predictive validity of the orebro musculoskeletal pain questionnaire. Clin J Pain. 2003;19(2):80-86.

53. Matsudaira K, Oka H, Kikuchi N, Haga Y, Sawada T, Tanaka S. The Japanese version of the STarT back tool predicts 6-month clinical outcomes of low back pain. J Orthop Sci. 2017;22(2):224-229.

54. Somers TJ, Keefe FJ, Pells JJ, et al. Pain catastrophizing and pain-related fear in osteoarthritis patients: relationships to pain and disability. J Pain Symptom Manage. 2009;37(5):863-872.

55. Ikemoto T, Miyagawa $\mathrm{H}$, Shiro $\mathrm{Y}$, et al. Relationship between biological factors and catastrophizing and clinical outcomes for female patients with knee osteoarthritis. World J Orthop. 2017;8(3):278-285.

56. Tajika T, Yamamoto A, Oya N, et al. Association between dysfunction of upper extremity and locomotive syndrome in general population. J Orthop Sci. 2017;22(1):144-148.

57. Albanese CV, Diessel E, Genant HK. Clinical applications of body composition measurements using DXA. J Clin Densitom. 2003;6(2): 75-85.

58. Bevier WC, Wiswell RA, Pyka G, Kozak KC, Newhall KM, Marcus R. Relationship of body composition, muscle strength, and aerobic capacity to bone mineral density in older men and women. $J$ Bone Miner Res. 1989;4(3):421-432.

59. Lindsey C, Brownbill RA, Bohannon RA, Ilich JZ. Association of physical performance measures with bone mineral density in postmenopausal women. Arch Phys Med Rehabil. 2005;86(6):1102-1107.

60. Rand T, Seidl G, Kainberger F, et al. Impact of spinal degenerative changes on the evaluation of bone mineral density with dual energy X-ray absorptiometry (DXA). Calcif Tissue Int. 1997;60(5):430-433.

61. Pappou IP, Girardi FP, Sandhu HS, et al. Discordantly high spinal bone mineral density values in patients with adult lumbar scoliosis. Spine (Phila Pa 1976). 2006;31(14):1614-1620.

62. Howe TE, Rochester L, Neil F, Skelton DA, Ballinger C. Exercise for improving balance in older people. Cochrane Database Syst Rev. 2011;(11):CD004963.

63. Kendrick D, Kumar A, Carpenter H, et al. Exercise for reducing fear of falling in older people living in the community. Cochrane Database Syst Rev. 2014;(11):CD009848.

64. Hashizume H, Yoshimura N, Nagata K, et al. Development and evaluation of a video exercise program for locomotive syndrome in the elderly. Mod Rheumatol. 2014;24(2):250-257.

65. Aoki K, Sakuma M, Ogisho N, Nakamura K, Chosa E, Endo N. The effects of self-directed home exercise with serial telephone contacts on physical functions and quality of life in elderly people at high risk of locomotor dysfunction. Acta Med Okayama. 2015;69(4):245-253.

66. Locomotive syndrome pamphlet; 2015. In: Locomotive Challenge! Council, Editors. Tokyo: Japanese Orthopaedic Association; 2016. Available from: https://locomo-joa.jp/en/index.pdf. Accessed December 1, 2017.

67. Hashimoto M, Yasumura S, Nakano K, et al. [Feasibility study of locomotion training in a home-visit preventive care program]. Nihon Ronen Igakkai Zasshi. 2012;49(4):476-482. Japanese. 
68. DiMatteo MR. Variations in patients' adherence to medical recommendations: a quantitative review of 50 years of research. Med Care. 2004;42(3):200-209.

69. Sabate E. Adherence To Long-Term Therapies: Evidence for Action. Geneva: World Health Organization; 2003. Available from: http://www. who.int/entity/chp/knowledge/publications/adherence_introduction. pdf. Accessed December 1, 2017.

70. Inoue $\mathrm{M}$, Ikemoto $\mathrm{T}$, Inoue $\mathrm{S}$, et al. Analysis of follow-up data from an outpatient pain management program for refractory chronic pain. J Orthop Sci. 2017;22(6):1132-1137.

71. Kamper SJ, Apeldoorn AT, Chiarotto A, et al. Multidisciplinary biopsychosocial rehabilitation for chronic low back pain: cochrane systematic review and meta-analysis. BMJ. 2015;350:h444.

72. Otani K, Takegami M, Fukumori N, et al; LOHAS Research Group. Locomotor dysfunction and risk of cardiovascular disease, quality of life, and medical costs: design of the Locomotive Syndrome and Health Outcome in Aizu Cohort Study (LOHAS) and baseline characteristics of the study population. J Orthop Sci. 2012;17(3):261-271.
73. Tominaga R, Fukuma S, Yamazaki S, et al. Relationship between kyphotic posture and falls in community-dwelling men and women: the locomotive syndrome and health outcome in Aizu Cohort Study. Spine. 2016;41(15):1232-1238.

74. Takada S, Yamamoto Y, Shimizu S, et al. Association between subjective sleep quality and future risk of falls in older people: results from LOHAS. J Gerontol A Biol Sci Med Sci. Epub 2017 Jun 17.

75. Kamitani T, Yamamoto Y, Kurita N, et al. Longitudinal association between subjective fatigue and future falls in community-dwelling older adults: the Locomotive Syndrome and Health Outcomes in the Aizu Cohort Study (LOHAS). J Aging Health. Epub 2017 Jul 1.

\section{Clinical Interventions in Aging}

\section{Publish your work in this journal}

Clinical Interventions in Aging is an international, peer-reviewed journal focusing on evidence-based reports on the value or lack thereof of treatments intended to prevent or delay the onset of maladaptive correlates of aging in human beings. This journal is indexed on PubMed Central, MedLine,

\section{Dovepress}

CAS, Scopus and the Elsevier Bibliographic databases. The manuscript management system is completely online and includes a very quick and fair peer-review system, which is all easy to use. Visit http://www.dovepress. $\mathrm{com} /$ testimonials.php to read real quotes from published authors. 